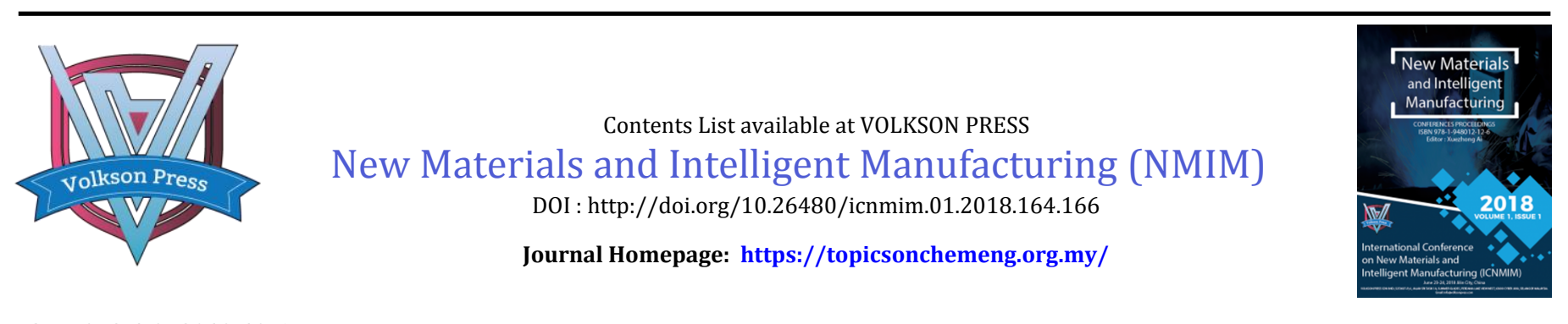

ISBN: 978-1-948012-12-6

\title{
THE SYNTHESIS AND CHARACTERIZATION OF SUCROSE MODIFIED MAGNETITE
}

\author{
Li Jin, Fangtong Liu, Jianpo Zhang* \\ School of Chemical and Pharmaceutical Engineering, Jilin Institute of Chemical Technology, Chengde Street 45\#, Jilin, China. \\ *Corresponding Author Email: canoe8013@126.com
}

This is an open access article distributed under the Creative Commons Attribution License, which permits unrestricted use, distribution, and reproduction in any medium, provided the original work is properly cited

\section{ARTICLE DETAILS}

\section{Article History:}

Received 26 June 2018

Accepted 2 July 2018

Available online 1 August 2018

\section{ABSTRACT}

Monodisperse air-stable sucrose modified magnetite $\left(\mathrm{SFe}_{3} \mathrm{O}_{4}\right)$ has been prepared by precipitation via a simple and facile hydrothermal reduction route, which was characterized by scanning electron microscopy transmission (SEM), electron microscopy (TEM), energy dispersive X-ray (EDX) spectroscopy, X-ray diffraction (XRD), FT-IR spectroscopy and vibrating sample magnetometry (VSM). SEM and TEM analysis showed the formation of $60-80$ $\mathrm{nm}$ particles. Hysteresis loops indicated that as prepared product could be separated from the nonmagnetic materials in a magnetic field. FT-IR spectra indicated that the carboxylate in this work might bind to the magnetite surface through two oxygen atom, and the sucrose modified magnetite $\left(\mathrm{SFe}_{3} \mathrm{O}_{4}\right)$ was rather stable.

\section{KEYWORDS}

Magnetite, sucrose modified, hydrothermal reduction, characterization.

\section{INTRODUCTION}

In the past decade, broad attention and research have been devoted to the design of the magnetic nanoparticles, which were consists of magnetic cores and polymeric shells. The high interests in magnetic nanoparticles are mainly related to they can be manipulated or recovered rapidly by an external magnetic field. Also due to their high surface area and excellent chemical selectivity magnetic nanoparticles are considered as potential adsorbents, which the particle shape, core size and surface functional groups can also be controlled [1,2]. By the choice and chemical modification of polymeric shells, the surface functionality of magnetic nanoparticles can be tailored for various applications in several fields (such as drug delivery, therapy, diagnosis, separation, enzyme immobilization and, etc) [3]. However, magnetic nanoparticles with hydrophobic surface properties and aggregation limit their dispersion into aqueous solutions and matrices, which also affect the chemical and physical reactivity toward interaction with other contacted species [4]. In order to overcome such limitations along with the maintenance of the magnetic properties of such nanoparticles, various selected approached are generally used to coat the particles with biocompatible, water-soluble and nontoxic materials [5-9].

In this paper, monodisperse air-stable sucrose modified $\mathrm{Fe}_{3} \mathrm{O}_{4}\left(\mathrm{SFe}_{3} \mathrm{O}_{4}\right)$ was synthesized using sucrose, $\mathrm{FeCl}_{3}$ and $\mathrm{NaBH}_{4}$. The structure, component, morphology and magnetic property of the composites were characterized by scanning electron microscopy (SEM), transmission electron microscope (TEM), fourier-transform infrared spectrometer (FTIR), X-ray Diffraction (XRD) and the energy dispersive X-ray (EDXA) spectrums and vibrating sample magnetometry (VSM).

\section{EXPERIMENTAL SECTION}

\subsection{Materials}

The chemical reagents used in this work are ferric chloride $\left(\mathrm{FeCl}_{3}\right)$, sucrose, methyl orange, and sodium borohydride $\left(\mathrm{NaHB}_{4}\right)$. All the chemical reagents are of analytical grade.
In a facile experimental procedure, $6 \mathrm{~g}$ of sucrose and $5 \mathrm{~g}$ of $\mathrm{FeCl}_{3}$ were dissolved in $15 \mathrm{~mL}$ of deionized water and nitrogen $\left(\mathrm{N}_{2}\right)$ was introduced into the solution for $20 \mathrm{~min}$, then $10 \mathrm{~mL} 0.01 \mathrm{~mol} / \mathrm{L} \mathrm{NaHB}_{4}$ was doped with vigorous stirring. The molar ratio of $\mathrm{NaHB}_{4}$ to $\mathrm{FeCl}_{3}$ is $1: 3$. Vigorous stirring was carried on for about $30 \mathrm{~min}$, and the obtained mixture was then transferred into a Teflon lined stainless steel autoclave $(25 \mathrm{~mL}$ capacity) for crystallization at $180{ }^{\circ} \mathrm{C}$ for $48 \mathrm{~h}$. After the reaction system was naturally cooled to room temperature, the product $\left(\mathrm{SFe}_{3} \mathrm{O}_{4}\right)$ was isolated from the liquid phase by magnetic and then thoroughly washed three times with deionized water to remove water-soluble organic byproducts. In order to remove un-encapsulated $\mathrm{Fe}_{3} \mathrm{O}_{4}$, the sample was dipped in $0.1 \mathrm{M} \mathrm{HCl}$ solution for $12 \mathrm{~h}$, then the product was isolated from the liquid phase by magnetic and dried at $60{ }^{\circ} \mathrm{C}$ overnight and black powder was obtained.

\section{RESULTS AND DISCUSSION}

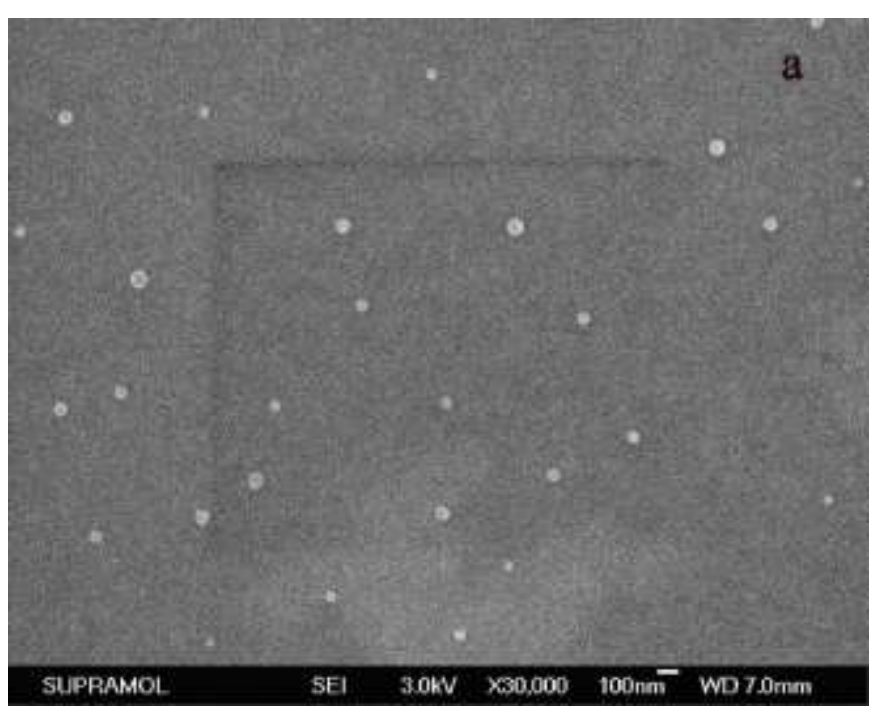

\subsection{Synthesis of zero valent iron in Sucrose}




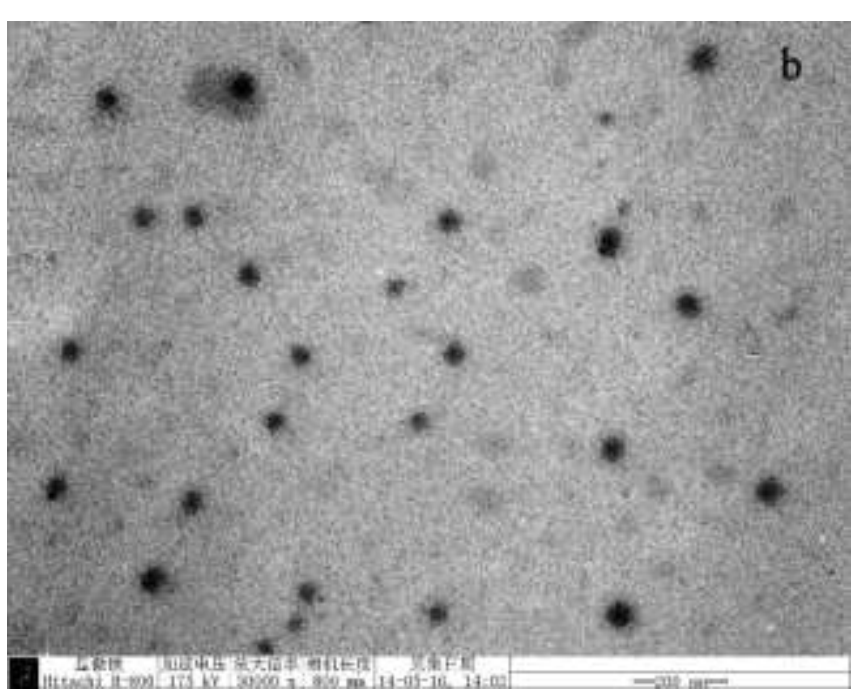

Figure 1: SEM (a) and TEM (b) image of the $\mathrm{SFe}_{3} \mathrm{O}_{4}$

The morphology of $\mathrm{SFe}_{3} \mathrm{O}_{4}$ was characterized by SEM. As shown in Figure 1 (a), the morphology of $\mathrm{SFe}_{3} \mathrm{O}_{4}$ was the fancy totally round spheres and shown the nearly uniform distribution of particle size (about $60-80 \mathrm{~nm}$ ). Figure 2(b) showed the TEM pictures of $\mathrm{SFe}_{3} \mathrm{O}_{4}$, in which $\mathrm{Fe}_{3} \mathrm{O}_{4}$ can be well encapsulated in the sucrose matrix, and most of the $\mathrm{Fe}_{3} \mathrm{O}_{4}$ were located in the core of the spheres.

Furthermore, the surface composition was analyzed using an EDXA attached to the SEM. The EDXA analysis (Figure 2) shows that the surface is primarily comprised of carbon (C) and oxygen (O). Figure 2 illustrates the EDXA spectrum of the $\mathrm{SFe}_{3} \mathrm{O}_{4}$ and the insert table shows the percentage of elements present. $\mathrm{C}$ was the most abundant element present at the surface, followed by 0 , and Fe was barely existing, which indicate that $\mathrm{Fe}_{3} \mathrm{O}_{4}$ was completely capped by sucrose.

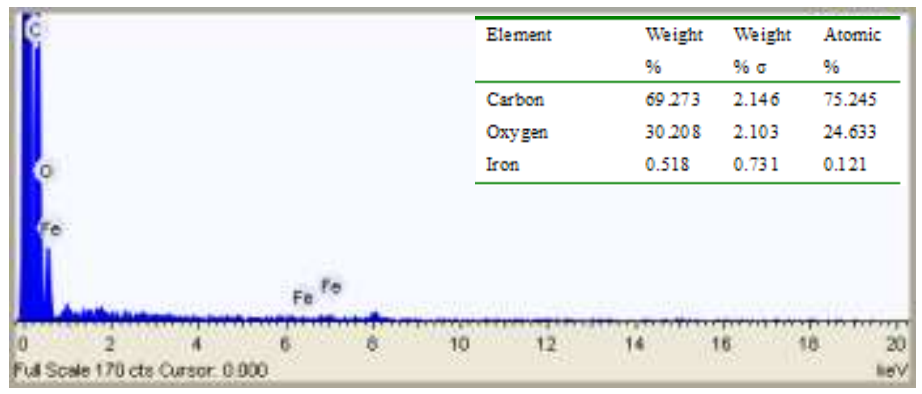

Figure 2: The energy dispersive X-ray (EDXA) spectrums for $\mathrm{SFe}_{3} \mathrm{O}_{4}$ particles

To identify the iron oxide phases of all the samples, the XRD pattern was adopted as shown in Figure 3. All the peak positions at 18.2 (111), 30.1 (200), 35.4 (311), 43.0 (400), 53.7 (422), 57.2 (511), and 62.6 (440) are consistent with the standard X-ray data for the magnetite phase (JCPDS no. 19-0629). The particle size calculated by Scherrer's equation is $75 \mathrm{~nm}$, which is quite close to the SEM and TEM result. It means that all the assynthesized particles are single crystals. Moreover, the relative XRD peak intensities increase with increasing sucrose concentration, as the molar ratio of sucrose to $\mathrm{FeCl}_{3}$ was 2:1 (sample a) and 1:3 (sample b) which indicates that the relative crystallinity of the magnetite increased. Besides magnetite peaks, we did not observe any other iron oxide peaks in the diffraction pattern for any of the samples.

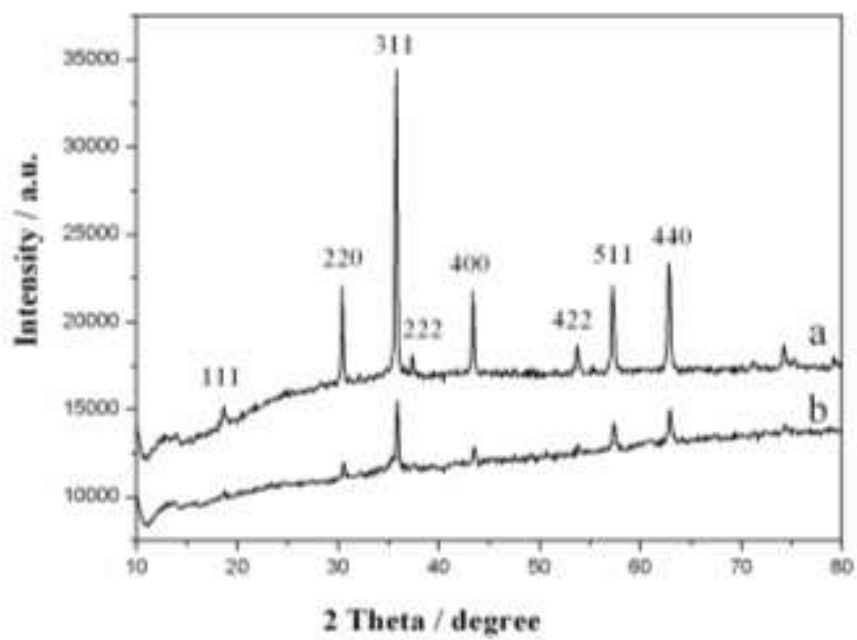

Figure 3: X-ray diffraction (XRD) of $\mathrm{SFe}_{3} \mathrm{O}_{4}$ sample a and b. The molar ratio of sucrose to $\mathrm{FeCl}_{3}$ was 2:1 (sample a) and 1:3 (sample b)

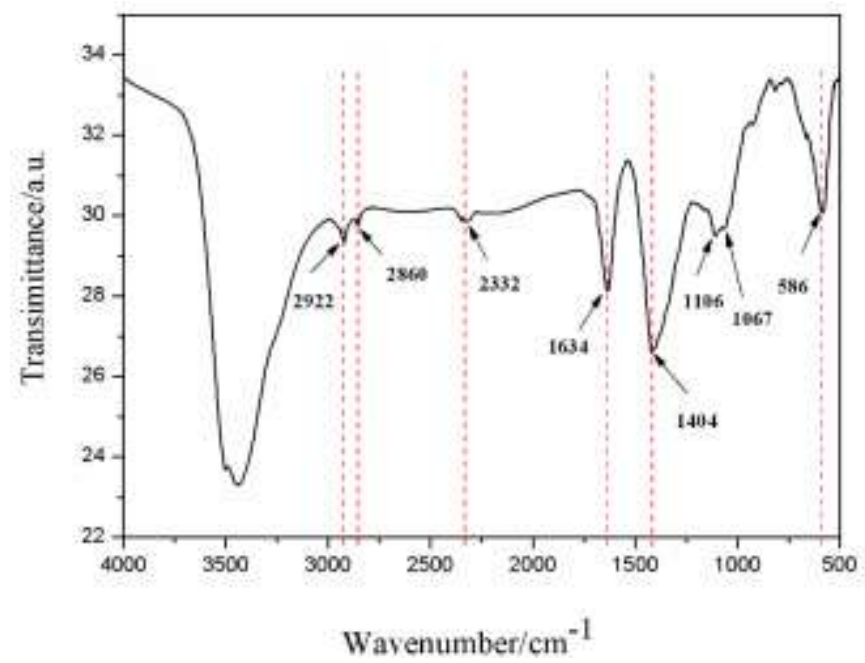

Figure 4: The FT-IR spectroscopy of $\mathrm{SFe}_{3} \mathrm{O}_{4}$ sample 
The FT-IR spectroscopy was introduced to analysis the presence of the coating agents on the surface of the $\mathrm{Fe}_{3} \mathrm{O}_{4}$. FT-IR spectroscopy of the asprepared $\mathrm{SFe}_{3} \mathrm{O}_{4}$ was shown in Figure 4. The broad characteristic band from 3600 to $3100 \mathrm{~cm}^{-1}$ could be assigned to $\mathrm{O}-\mathrm{H}$ stretching vibration arising from hydroxyl groups on nanoparticles and adsorbed glucose, gluconic acid, and water [10]. The peaks around $2922 \mathrm{~cm}^{-1}$ and $2860 \mathrm{~cm}^{-1}$, assignable to asymmetric and symmetric vibrations of $\mathrm{C}-\mathrm{H}$ in $-\mathrm{CH}_{2-}^{-}$, can be obviously found [11]. Characteristic bands at $2922 \mathrm{~cm}^{-1}$ (asymmetric stretching) and $2850 \mathrm{~cm}^{-1}$ (symmetrical deformation vibration) of $\mathrm{C}-\mathrm{H}$ in $\mathrm{CH}_{3}$ might arise from the side reaction products of sucrose during the hydrothermal reaction. The band at $1261 \mathrm{~cm}^{-1}$ of $-\mathrm{COOH}$ stretching, at $1102 \mathrm{~cm}^{-1}$ of C-O-C stretching and at $679 \mathrm{~cm}^{-1}$ of $-\mathrm{C}-\mathrm{H}$ all came from the residue sucrose. In addition, the absorption band at $2332 \mathrm{~cm}^{-1}$ on the spectrum referred to the vibration of the adsorbed $\mathrm{CO}_{2}$ in the sample. The absorption band at $1634 \mathrm{~cm}^{-1}$ on the spectrum referred to the vibration of - $\mathrm{FeOO}$ stretching vibration, which indicated the existence of active hydroxyl group, which indicated that the carboxylate in this work might bind to the magnetite surface through two oxygen atom. The band at 586 $\mathrm{cm}^{-1}$ is related to the vibrations of the Fe-O functional group, which corroborates that the phase of as-prepared particles is magnetite [12].
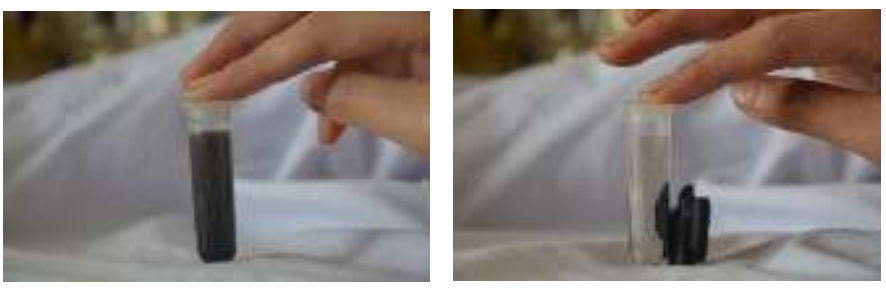

Figure 5: Photography image of $\mathrm{SFe}_{3} \mathrm{O}_{4}$ solution with (a) and without an external magnetic field (b)

Magnetic property of $\mathrm{SFe}_{3} \mathrm{O}_{4}$ was also characterized. As shown in Figure5, with the external magnetic field, the $\mathrm{SFe}_{3} \mathrm{O}_{4}$ will soon be sucked, and the solution is clear; and after removed this external magnetic field, $\mathrm{SFe}_{3} \mathrm{O}_{4}$ fall rapidly and return to a homogeneous $\mathrm{SFe}_{3} \mathrm{O}_{4}$ solution, indicated that the materials have the properties of magnetism. And magnetization curves of the samples measured at room temperature was shown in Figure 6. The saturation magnetization (Ms) of the samples $80.47 \mathrm{emu} / \mathrm{g}$, retentivity $(\mathrm{Mr})$ is $13.88 \mathrm{emu} / \mathrm{g}$ and coercivity $(\mathrm{Hc})$ is 83.52 G. Attributed to the existence of organic coating agent, the saturation magnetization of the samples is smaller than the bulk magnetite $(92 \mathrm{emu} / \mathrm{g})$, which is often observed with the nanoparticles. Some references revealed that due to quenching of surface moments of the coating agents the uniformity of the samples was decreased, resulting in the reduction of magnetic moment in the samples [13].

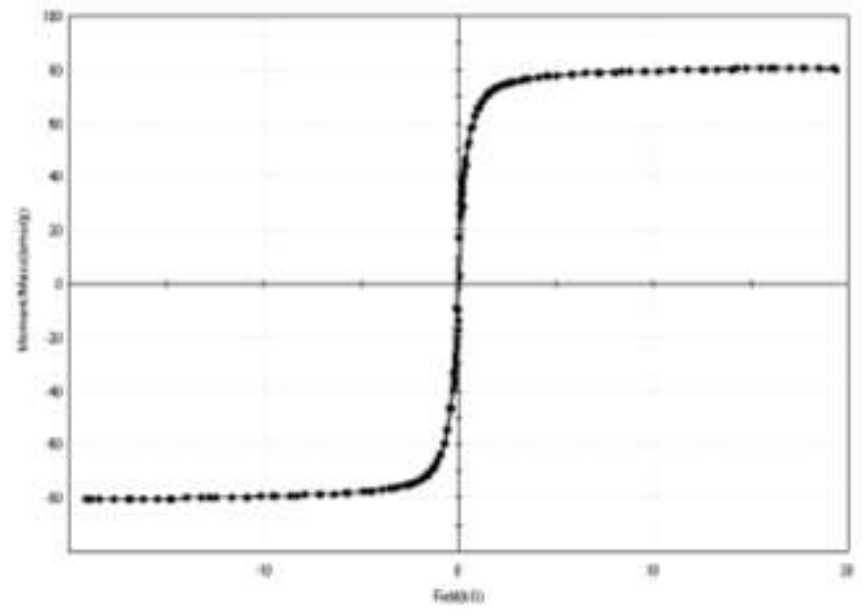

Figure 6: Magnetization curves at room temperature of magnetite samples

\section{CONCLUSIONS}

In this paper, monodisperse air-stable $\mathrm{Fe}_{3} \mathrm{O}_{4}$ nanocrystal encapsulated in sucrose has been successfully synthesized via a simple and facile hydrothermal reduction route. Sucrose both acted as reducing agent and coating agent, which prevent particle growth and agglomeration by chelating with metal ions. Results indicated $\mathrm{SFe}_{3} \mathrm{O}_{4}$ could be separated with the help of external magnetic field. Therefore, with the help of an applied magnetic field as-prepared product can be used as a powerful adsorbent for different applications.

\section{ACKNOWLEDGEMENTS}

This work was financially supported by the national natural science foundation of china (No. 21405058).

\section{REFERENCES}

[1] Wei, L., Yang, G., Wang, R., Ma, W. 2009. Selective adsorption and separation of chromium (VI) on the magnetic iron-nickel oxide from waste nickel liquid [J]. Journal of Hazardous Materials, 164, 1159-1163. doi: 10.1016/j.jhazmat.2008.09.016

[2] Hu, J., Chen, G.H., Lo, I.M.C. 2006. Selective removal of heavy metals from industrial wastewater using maghemite nanoparticle: performance and mechanisms [J]. Journal of Environmental Engineering ASCE, 132 (7), 709-715.

[3] Lai, B.H., Yeh, C.C., Chen, D.H. 2012. Surface modification of iron oxide nanoparticles with polyarginine as a highly positively charged magnetic Nano-adsorbent for fast and effective recovery of acid proteins [J]. Process Biochemistry, 47, 799-805. doi: 10.1016/j.procbio.2012.02.010

[4] Jiang, F., Fu, Y., Zhu, Y., Tang, Z., Sheng, P. 2012. Fabrication of iron oxide/silica core-shell nanoparticles and their magnetic characteristics [J]. Journal of Alloys and Compounds, 543, 43-48. doi: 10.1016/j.jallcom. 2012.07.079

[5] Hua, M., Zhang, S., Pan, B., Zhang, W., Lv, L., Zhang, Q. 2012. Heavy metal removal from water/wastewater by nanosized metal oxides: a review [J] Journal of Hazardous Materials, 211-212, 317-331. doi: 10.1016/j.jhazmat.2011.10.016

[6] Xu, P., Zeng, G.M., Huang, D.L., Feng, C.L., Hu, S., Zhao, M.H., Lai, C., Wei, Z., Huang, C., Xie, G.X., Liu, Z.F. 2012. Use of iron oxide nanomaterials in wastewater treatment: a review [J]. Science of the Total Environment, 424, 1-10. doi: 10.1016/j.scitotenv.2012.02.023

[7] Li, L., Fan, M.H., Brown, R.C., Van Leeuwen, J.H., Wang, J.J., Wang, W.H., Song, Y.H., Zhang, P.Y. 2006. Synthesis, properties, and environmental applications of nanoscale iron-based materials: a review [J]. Critical Reviews in Environmental Science and Technology, 36, 405-431. Doi: /10.1080/10643380600620387

[8] Kim, M., Chen, Y., Liu, Y., Peng, X. 2005. Super-stable, high-quality $\mathrm{Fe}_{3} \mathrm{O}_{4}$ dendron- nanocrystals dispersible in both organic and aqueous solutions [J]. Advanced Materials, 17, 1424-1432. doi: 10.1002/adma. 200401991

[9] Wang, L.Y., Bao, J., Wang, L., Zhang, F., Li, Y.D. 2006. One-pot synthesis and bio application of amine -functionalized magnetite nanoparticles and hollow nanospheres [J]. Chemistry: A European Journal, 12, 6341-6347. doi: 10.1002/chem.200501334

[10] Giasuddin, A.B.M., Kanel, S.R., Choi, H. 2007. Adsorption of Humic acid onto nanoscale zero-valent iron and its effect on arsenic removal [J]. Environmental Science \& Technology, 41, 2022-2027. doi: $10.1021 /$ es0616534

[11] Cai, W., Wan, J.Q.J. 2007. Facile synthesis of superparamagnetic magnetite nanoparticles in liquid polyols [J]. Journal of Colloid and Interface Science, 305, 366-370. doi: 10.1016/j.jcis.2006.10.023

[12] Cornell, R.M., Schwertmann, U. 1996. The iron oxides. [D] Wiley-VCH: Weinheim, Germany, doi: 10.1002/3527602097.ch1

[13] Kim, D.K., Mikhaylova, M., Zhang, Y., Muhammed, M. 2003. Protective coating of superparamagnetic iron oxide nanoparticles [J]. Chemistry of Materials, 15, 1617-1627. doi: 10.1021/cm 021349j 